\title{
A Counselor's Cultural Identity: Implications from A Multicultural Counseling Perspective in Malaysia
}

\author{
Ng Jia Ying ${ }^{1}$, Siti Aishah Hassan ${ }^{1}$, Dzilal Abdul Aziz ${ }^{1}$ \\ ${ }^{1}$ Department of Counselor Education and Counseling Psychology, Faculty of Educational Studies, Universiti \\ Putra Malaysia, Serdang, Selangor, Malaysia \\ Correspondence: Siti Aishah Hassan, Department of Counselor Education and Counseling Psychology, Faculty \\ of Educational Studies, Universiti Putra Malaysia, 43400 UPM Serdang, Selangor, Malaysia. Tel: \\ 603-9769-8210. E-mail: siti_aishahh@upm.edu.my
}

Received: September 3, 2021 Accepted: September 28, 2021 Online Published: October 14, 2021

doi:10.5539/ass.v17n11p18 URL: https://doi.org/10.5539/ass.v17n11p18

\begin{abstract}
Malaysia is a country with a diversified cultural background, ethnicities, and religions. Islam is the most widely practiced religion, followed by Buddhism, Christianity, Hinduism, other traditional Chinese religions, as well as other indigenous religions. Despite the richness of the cultural landscape, the counseling services in Malaysia seem to be very limited in terms of diversification of multiculturalism. Cultural relevance of counselling theories, adaptation of Western-trained counseling services to suit a Malaysian culture, and multicultural counseling competencies, are among the concerns in the profession. This paper focuses on factors that shape a counselor's identity based on their cultural background, and its implications on multicultural counseling in Malaysia. Among the important factors highlighted in this paper are religious beliefs and values, locus of control, gender, and personality. This paper encapsulates the importance of understanding a counselor's cultural identity for the effectiveness of multicultural counseling in Malaysia.
\end{abstract}

Keywords: Multicultural, counseling, culture identity, multicultural counseling competency, multi-religious country, Malaysia, gender, personality.

\section{Introduction}

Malaysia is a country with a diversified cultural landscape, particularly in terms of ethnicity and religion. According to the most recent demographic data (Department of Statistics Malaysia, 2021), the Malaysian population is divided into three major races: Bumiputera (69.7\%), Chinese (22.5\%), Indian (6.8\%), and other ethnic minorities. As Malaysia is a secular state, its residents are allowed to practice their religion freely. Of all the religions in Malaysia, Islam is the most widely practiced religion (61.3\%), followed by Buddhism (19.8\%), Christianity (9.2\%), Hinduism (6.3\%), traditional Chinese religions $(1.3 \%)$, and indigenous religions $(0.4 \%)$, which are based on the 2020 Population and Housing Census of Malaysia (Department of Statistic Malaysia, 2011).

In contrast to the richness of the cultural landscape presented, the counseling services in Malaysia seem to only represent a low level of cultural and social integration (See \& Ng, 2010). Researchers have pointed out that the contemporary status of multicultural counseling in Malaysia remains unclear, due to the lack of studies in this field (Voon \& Jaladin, 2017). Besides, Rafidah Aga Mohd Jaladin et al. (2020) have listed a few serious concerns about (a) cultural relevance of counselling theories applied by Malaysian counsellors, (b) the extent of adjustment or modification, made by Western-trained counsellors based on Malaysian's culture, and (c) the status of multicultural counseling practices among professional counsellors. Therefore, it is suggested that there is an imminent need for Malaysian professional counsellors to improve their multicultural counseling competencies. In addition, for the efficacy of counseling to maintain relevance to the intended population, cultural norms must be considered (Khoshbooii et al., 2021)

As the old mantra goes "know thyself", Derald Wing Sue \& Sue (2016) stressed that mental health professionals who are culturally competent, are those who are actively learning about their own beliefs, biases, preconceptions about human behavior, preconceived notions, personal limitations, and so on. Therefore, it is imperative for counsellors to examine their own cultural identity. In some psychological literature, cultural identity has been simplified to a single component, such as racial identity, gender identity, and sexual identity. As a matter of fact, 
cultural identity is multidimensional, and certain components of a client's cultural identity might influence his/her manner of presenting a problem (Ibrahim \& Heuer, 2013). Likewise, a counsellor's interpretation or diagnosis in counseling might also be affected by some aspects of the counselor's own identity, if there is no awareness.

In this paper, the author will discuss the importance of a counsellor's self-awareness of his/her own cultural identity in terms of multicultural counseling. In particular, the discussion will focus on three aspects of identities, namely (1) religious beliefs or values; (2) worldview, i.e., locus of control and responsibilities; and (3) gender and personality.

\section{Religious Beliefs and Values}

Before diving into the discussion on the counsellor's cultural identity of religious beliefs and values, it is important to be aligned on the definition of spirituality and religion. Although spirituality and religion are often used interchangeably, these terms carry different meanings. Spirituality refers to a state of being attuned with God, or the Divine Intelligence that governs or harmonizes the universe (Richards \& Bergin as cited in Cornish et al., 2010). On the other hand, religion is often defined as an organized system of faith, worship, cumulative traditions, and prescribed rituals (Worthington as cited in Cornish et al., 2010). In other words, spirituality is more of an individual practice that involves a sense of peace and purpose, while religion is a specific set of organized beliefs and practices. Examples of popular religions in the world are Islam, Christianity, Hinduism, Buddhism, and Judaism.

As mentioned in the first section, Malaysia is a multiracial and multireligious nation, where most of its people have a religious belief $(98.3 \%)$. Not only that, researches have also supported the notion that religion is beneficial to one's mental health, of which, around $80 \%$ of religion and health research works have studied mental health, and most of them found a link between religion, and a reduced risk of mental illnesses and disorders (as cited in Tan et al., 2020). Therefore, it is crucial for mental health professionals to acquire the spiritual/religious ( $\mathrm{S} / \mathrm{R}$ ) competence to provide better mental health services in diverse societies. The Association of Spiritual, Ethical and Religious Values in Counseling (ASERVIC) (2009) have identified 14 areas on competent practice, organized around six categories: (1) cultural and worldview; (2) counselor self-awareness; (3) human and spiritual development; (4) communication; (5) assessment; and (6) diagnosis and treatment (As cited in Cashwell \& Young, 2011). The details of the six categories of S/R competent practice can be seen in Diagram 1. Cashwell \& Young (2011) highlighted that self-awareness competencies should come before the clinical application of such competencies. This is to say, the counselor's self-awareness is required for a culturally competent practice, and that counsellors are unlikely to respond to their client's spiritual/religious ( $\mathrm{S} / \mathrm{R}$ ) concerns well enough without self-awareness. In this section, the barriers for such competencies in S/R counseling will be examined. The knowledge, skills, values, and attitudes required for the competency in $S / R$ issues will be discussed, followed by some guidelines or advice for counsellors on multiple $S / R$ issues.

For a variety of reasons, mental health practitioners may find it challenging to integrate $S / R$ factors, or to address $\mathrm{S} / \mathrm{R}$ issues during the counseling sessions. To begin with, many mental health practitioners believe they are unprepared to deal with S/R concerns in counseling (as cited in Cornish et al., 2010). This phenomenon is consistent with barriers in multicultural counseling faced by Malaysia's counsellors. According to Rafidah Aga Mohd Jaladin (2013), it has been reported that (a) participant counsellors perceived themselves as less multiculturally competent, particularly when it involves different religions; and (b) many participants find issues such as lesbian lifestyle, premarital sex, or extramarital sex, as culturally sensitive and challenging. Secondly, it was found that even mental health practitioners who believe it is critical to address $S / R$ concerns in psychotherapy, engaged in these practices less frequently, than one might assume (Frazier \& Hansen, 2009). A Psychotherapist's resistance in discussing S/R topics may also come up because they have not personally investigated it. Moreover, a psychotherapist may not view $S / R$ issues as a significant factor in their client's lives, since most of them have not indicated that religion is an important factor in their lives (as cited in Cornish et al., 2010). Counsellors who hold different religious belief with their clients may find it challenging to agree on a particular S/R viewpoint, or they may avoid discussing religious and spiritual identities out of the desire to respect the individual's belief system, or avoid it out of fear of being influenced by the client's beliefs. From an anecdote of a Malaysian Experience of Triad Training Model (Hassan \& Peh, 2014), a Malaysian Buddhist counselor trainee had reported difficulty to display empathy towards his Christian client, due to his lack of the Bible's knowledge. Also, the therapeutic process of counseling had been impeded due to the trainee's fear of being converted into a Christian by the client. 


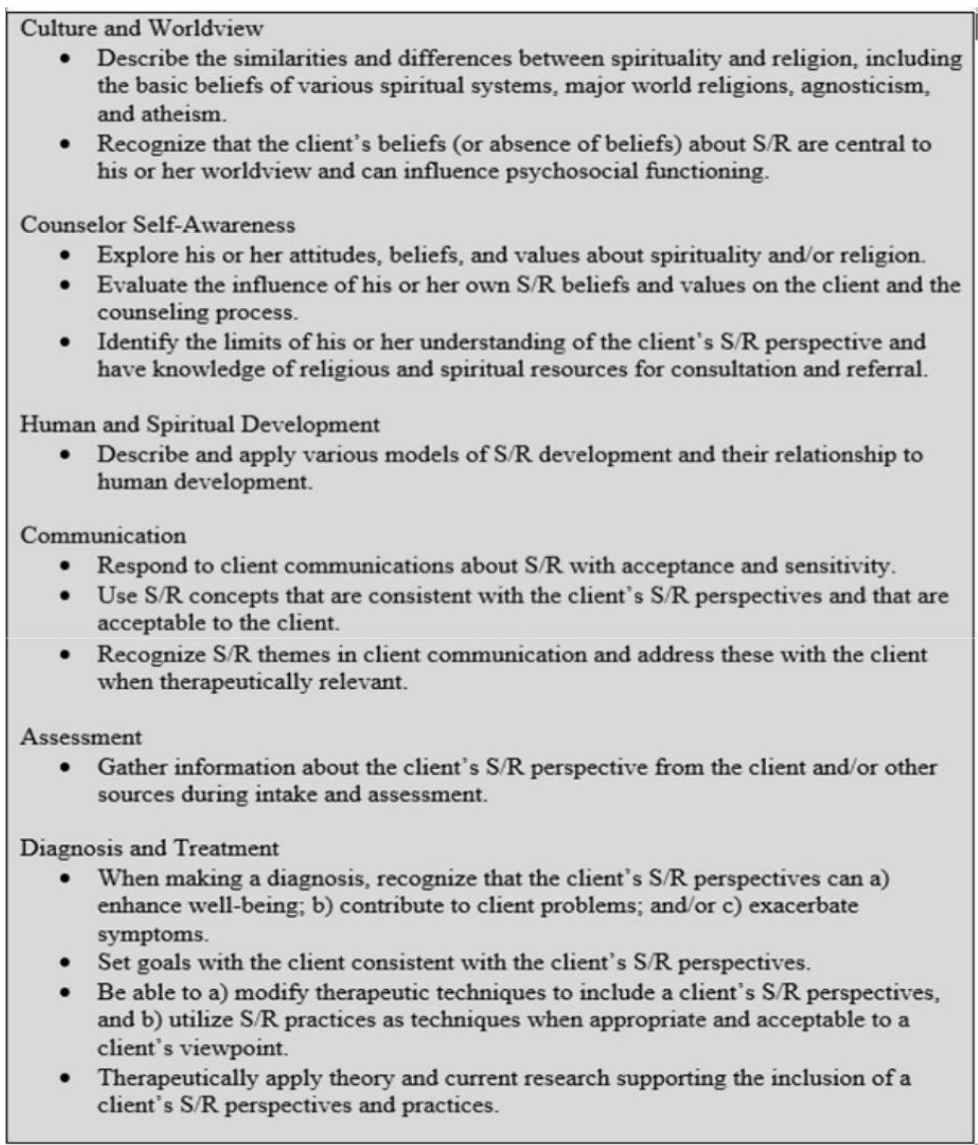

Figure 1. Religious and Spiritual Competencies for Counselors (Source: Cornish et al., 2010)

In essence, these barriers and challenges can be reduced if mental health professionals increase their cultural competencies from across three major domains: (1) knowledge; (2) skills; and (3) values and attitudes. To be a $\mathrm{S} / \mathrm{R}$ competent counselor, one should acquire knowledge of major Western and Eastern religious traditions, and understand the normative components within these belief systems. One must also be familiar with the S/R concepts (e.g., human nature, morality, etc.) and language (e.g., sin, reincarnation, karma, zakat, samsara, etc.) that are employed in these traditions. To foster a brief understanding on the four major religions in Malaysia, Table 1 displays a brief outline of the S/R concepts, and issues relevant in therapy for Islam, Buddhism, Hinduism, and Christianity. Apart from the major religions, counsellors should not overlook the significance of indigenous healing, or alternative therapies in different cultures, because a big number of the world population still depends on alternative and complementary therapies for health and healing. From a Malaysian context, many still believe in alternative therapies, such as treatment from Bomohs, Traditional Chinese Medicine (TCM), Ayurveda, and prayer healing. In fact, studies have shown that a high percentage of Pharmacy students used (57.8\%), or had previously used at least one type of Complementary and Alternative Medicine (CAM, 77.6\%) (Hassan et al., 2011). Therefore, counsellors must be mindful of the need to respect such cultural belief systems. For instance, if one believes that mental illness is caused by psychological factors, counselling or therapy may be recommended. However, if one believes that abnormal behaviour is caused by other forces (e.g., supernatural), the client may benefit from also consulting a spiritual leader or healer from the client's faith (Cornish et al., 2010; Lim et al., 2018). Even if the counselor and client share a common culture, religion, or spiritual traditions, they might have vastly different $S / R$ beliefs, practices, and worldviews. For example, not all Buddhists are vegetarians, and the consumption of meat is not condemned in Buddha's teachings. For this reason, counselors must make careful cultural assessments (e.g., level of religious orthodoxy, acculturation, intersection of cultural and family issues) before creating a culturally appropriate treatment plan.

Apart from gaining general knowledge about religions, counsellors must also examine what the religion means to them personally. Counsellors should be able to answer existential questions, such as "Who am I? Where did I come from? Where am I going? What does life mean? What is worth living for?" (Helminiak, as cited in 
Cashwell \& Young, 2011). Only when counsellors acknowledge the spiritual implications of issues such as relationships with God or higher powers, can they effectively explore such issues with their clients. Counselors should always do self-reflection, so as to identify their values and biases, because most of the time our values and biases operate unconsciously. If the counsellor has religious beliefs that are different from what the client has, the counsellor must be mindful of, and try all means to avoid value imposition toward the client. However, it does not mean that one should not be mindful when he/she shares similar beliefs with that of the client, because they might share the same blindspot. Such blindspots, if not identified, might reinforce a client's unhealthy cognitive or behaviour. To conclude, it is of paramount importance for counsellors to become aware of their S/R beliefs, biases, and attitudes. At the same time, counsellors should establish an open and accepting attitude towards the client's belief system, and work within the client's value framework. If there are countertransference reactions that are unresolvable, counsellors should consider referring their clients to other suitable mental health professionals.

Table 1. Major Religions in Malaysia

\begin{tabular}{|c|c|c|c|c|}
\hline Beliefs & Islam & Buddhism & Hinduism & Christianity \\
\hline $\begin{array}{l}\text { View } \\
\text { Deity }\end{array}$ & $\begin{array}{l}\text { One God, Allah, creator } \\
\text { of all things in the } \\
\text { universe. All powerful, } \\
\text { all seeing, and all } \\
\text { knowing. Each person is } \\
\text { individually responsible } \\
\text { to Allah. }\end{array}$ & $\begin{array}{l}\text { Buddhists do not worship } \\
\text { a God. Siddharta } \\
\text { Gautama became the } \\
\text { Buddha ("the } \\
\text { Enlightened One" in } \\
\text { Sanskrit). People pray to } \\
\text { good and evil deities. }\end{array}$ & $\begin{array}{l}\text { There is One Supreme } \\
\text { God with many forms } \\
\text { (male and female, } \\
\text { sucah as Vishnu and } \\
\text { Shiva). Dharma is the } \\
\text { cosmic law that directs } \\
\text { all processes in the } \\
\text { universe. }\end{array}$ & $\begin{array}{l}\text { Holy Trinity: Father, Son } \\
\text { and Holy Spirit. God: All } \\
\text { knowing, loving, Creator. } \\
\text { Jesus is the messiah who } \\
\text { died to atone for human } \\
\text { sins and offer salvation. }\end{array}$ \\
\hline
\end{tabular}

\begin{tabular}{|c|c|c|}
\hline $\begin{array}{l}\text { Beliefs and } \\
\text { Tenets of } \\
\text { the } \\
\text { Religion }\end{array}$ & $\begin{array}{l}\text { People are inherently } \\
\text { good. Humans have free } \\
\text { will to choose good or } \\
\text { evil. Belief in } \\
\text { predestination: much is } \\
\text { preordained by Allah. All } \\
\text { are to follow the Five } \\
\text { Pillars of Islam: } \\
\text { profession of faith, ritual } \\
\text { player five times/day } \\
\text { with ritual cleansing, } \\
\text { Ramadan and, } \\
\text { palmsgiving, fast, }\end{array}$ & $\begin{array}{l}\text { Each person creates his } \\
\text { or her own happiness and } \\
\text { is the product of his or } \\
\text { her own actions. Karma } \\
\text { is created by positive and } \\
\text { negative actions that } \\
\text { determine the next life, or } \\
\text { incarnation. Belief in the } \\
\text { "middle way" or "all } \\
\text { things in moderation", so } \\
\text { asceticism is rejected. } \\
\text { Follow the Eightfold } \\
\text { Path. }\end{array}$ \\
\hline
\end{tabular}

\begin{tabular}{|c|c|}
\hline View & $\begin{array}{l}\text { Good and bad deeds will } \\
\text { be reviewed by Allah on }\end{array}$ \\
\hline Life after & Judgement Day and \\
\hline Death & $\begin{array}{l}\text { individuals are consigned } \\
\text { to Paradise or to Hell. }\end{array}$ \\
\hline
\end{tabular}

\begin{tabular}{|c|c|}
\hline $\begin{array}{l}\text { Religious } \\
\text { Practices }\end{array}$ & $\begin{array}{l}\text { Prayer, meditation, and } \\
\text { reading Holy writings. } \\
\text { Restrictions: alcohol and } \\
\text { products of swine and } \\
\text { carrion. The Immam is } \\
\text { the prayer leader in the } \\
\text { mosque. }\end{array}$ \\
\hline
\end{tabular}

Belief in reincarnation. Based upon accumulated Karma, assigned to a better new life or a worse one.
Humans are divine and the only need to uncover their illusions. All things are holy because they come from a single sacred source and are one. The world is full pf change, struggle and suffering. Belief in the Karma, the law of cause and effect. Strong tradition in asceticism.

Only God's grace can free people from sin. Humans have free will and must choose good over evil. Christians are to follow the Ten Commandments and the teachings of the Gospels. God will provide for those who believe.

Eternal life after death.

Belief in reincarnation. Based upon accumulated Karma, assigned to a better new life or a worse one.

Meditation,

Meditation, prayer offerings, working with guru, daily worship, participating in festivals and rituals. Prayer at shrines, temples and family altars. Buddhists are vegetarians and do not kill any form of life.
Meditation, daily mantras, chanting asceticism, pilgrimages, yoga practice, offerings (flowers, fruits, etc.) and worship of deities. Devout Hindus do not kill any form of life as it may be a reincarnated soul.

Marriage is a sacrament and a religious duty-alliance between families. Marriage arranged. Traditional hindu families are patriarchal. In India, selective abortion may
After God's judgement, will be consigned to Heaven or Hell. Christians focus on life after death as the ultimate goal.

Living is a moral life, accepting Jesus and prayer brings one closer to God. Most denominations have two sacrements: baptism and communion. Others (e.g. Catholic) include reconcilitiation

("confession'), confirmation and marriage.

Fundamentalist

Christians, Evangelicals and Catholics do not condone divorce, abortion or premarital sex and they believe that homosexual acts are sinful. They may also 


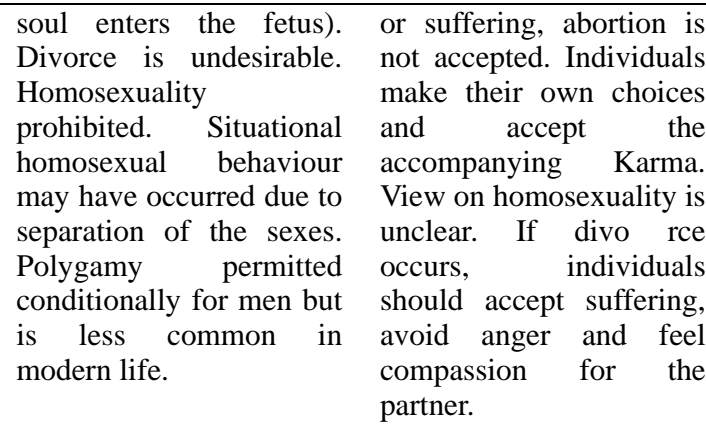

\begin{tabular}{|c|c|}
\hline \\
\hline & \multirow{6}{*}{$\begin{array}{lrlr}\text { be performed. } & \text { have more traditional } \\
\text { Premarital sex not } & \text { gender-role } & \begin{array}{r}\text { beliefs. } \\
\text { condoned. Caste system }\end{array} & \text { Many liberal Protestant } \\
\text { determines suitable } & \text { churches are more } \\
\text { marriage partners, } & \text { accepting of premarital } \\
\text { social roles and type of } & \text { sex, birth control, } \\
\text { work. Ancient Hindu } & \text { abortion, homosexuality } \\
\text { texts refer to and divorce. }\end{array}$} \\
\hline & \\
\hline \multirow{4}{*}{$\begin{array}{l}\text { be performed. } \\
\text { Premarital sex not } \\
\text { condoned. Caste system } \\
\text { determines suitable } \\
\text { marriage partners, } \\
\text { social roles and type of } \\
\text { work. Ancient Hindu } \\
\text { texts refer to }\end{array}$} & \\
\hline & \\
\hline & \\
\hline & \\
\hline \multirow{2}{*}{\multicolumn{2}{|c|}{$\begin{array}{l}\text { homosexuality } \\
\text { acceptable; in }\end{array}$}} \\
\hline \multirow{2}{*}{\multicolumn{2}{|c|}{$\begin{array}{l}\text { acceptable; in current } \\
\text { culture, there is a } \\
\text { negative }\end{array}$}} \\
\hline & \\
\hline \\
\hline
\end{tabular}

\section{Locus of Control}

In addition to a client's social identities and religious beliefs, counselors should also recognize clients as individuals with their own unique experience of the world. This is where the concept of worldview comes in. Worldviews are significantly associated with a person's cultural background and life experiences, and they impact how people interpret or perceive the world, and their relationship with the world (Koltko-Rivera, 2004). Although, worldview is identified by different names in literature (e.g., philosophy of life, vision of reality), worldview can be defined as follows:

"A worldview is a way of describing the universe and life within it, both in terms of what is and what ought to be. A given worldview is a set of beliefs that includes limiting statements and assumptions, regarding what exists and what does not (either in actuality, or in principle), what objects or experiences are good or bad, and what objectives, behaviors, and relationships are desirable or undesirable. A worldview defines what can be known or done in the world, and how it can be known or done. In addition to defining what goals can be sought in life, a worldview defines what goals should be pursued. Worldviews include assumptions that may be unproven, and even unprovable, but these assumptions are superordinate, in that they provide the epistemic and ontological foundations for other beliefs within a belief system." (Adapted from Koltko-Rivera, 2000, p. 2, as cited in Koltko-Rivera, 2004).

In other words, the worldview is made up of our attitudes, values, ideas, and conceptions. Not only so, but they also influence how we think, define occurrences in life, decide things, and act. Furthermore, in Malaysian context worldview, authoritarian parenting, which is characterised by high control and rigid limit setting, was found to be connected with a higher internal locus of control in Malay adolescents, rather than being a potentiating factor for external locus of control. This data supports the theory that children's interpretations of parenting approaches are influenced by their cultural setting (Keshavarz \& Baharudin, 2013).

It is undeniable that the worldview is a difficult concept. Nevertheless, frameworks like Kluckhohn and Strodtbeck's Value Orientation Model, Coan's "Basic Assumptions" Model and/or Sue's Fourfold Loci Model might help to clarify its key dimensions. For instance, Kluckhohn and Strodtbeck's Value Orientation Model has identified six areas, where the counsellor and client's worldviews may differ significantly: their ideas about the character of innate human nature (i.e., human nature orientation), their view on the mutability of human nature orientation (i.e., mutability orientation), their perspectives on human beings relations to nature (i.e., "Man-nature" orientation), how they experience and value time (i.e., time orientation), their attitudes toward activity (i.e., activity orientation), and their perspectives on social relationships (i.e., relational orientations) (F. Ibrahim \& Heuer, 2016; Koltko-Rivera, 2004). Coan's "Basic Assumptions" Model proposed essential aspects of worldview, which included voluntarism, determinism, biological determinism, environmental determinism, finalism, mechanism, emphasis on unconscious motivation versus emphasis on conscious motivation, religion, productivities versus spontaneity, relativism versus absolutism, and adventurous optimism versus resignation (Koltko-Rivera, 2004).

Sue (1978) highlighted that cultural blindness would likely continue to exist within the counseling profession if there is no theory on cultural oppression, and its relevance to the development of worldviews. The author posited that, counsellors or any helping professionals who have a different worldview than their clients, and are unaware of the grounds for this difference, are much more prone to view clients through a negative lens, and to engage in cultural oppression. For instance, a Western educated counselor who holds an individualistic view might perceive that his Asian client who holds a collectivistic view, may be passive and ineffective when his client is unable to make career decisions due to the parent's objection to his client's desired choice. To provide a model 
that enables a counselor's better understanding on the key dimensions of worldview, Sue (1978) proposed a fourfold loci model made up of two theoretical frames, which are crucial in the development of worldviews: (a) locus of control; (b) locus of responsibility.

The notion of locus of control was first proposed by Rotter (1966), and it pertains to people's perceptions of their level of control over their lives. It can be conceptualized as having two dimensions; internal and external. An individual who has an internal locus of control (IC) believes that he/she is in control of his/her destiny, and that reinforcements are conditional on our behaviors. In contrast, an individual who holds an external locus of control (EC) believes that life is beyond his/her control, and depends on luck, chance, or other unpredictable mechanisms (Sue \& Sue, 2016). Research suggests that high internality is linked with (a) a larger attempt at mastering the environment, (b) reduced predisposition to anxiety (c) higher success drive (d) greater social action involvement, and (e) emphasizing more on skill-determined rewards (Sue, 1978). In general, these are the attributes which are highly prized in an American society, and are the defining characteristic of Western mental health, i.e., people with these attributes are considered psychologically healthier, and vice versa. However, studies revealed that those of color, women, and people from low socioeconomic status have a relatively lower score on internality. If such an I-E dimension is used as a criterion for mental health, people of color, the poor, and female clients would be perceived as having fewer desirable traits. As a result, a counsellor who sees a minority client with a high externality may misinterpret the client as being indifferent, procrastinating, lazy, or does not dare to try. Nonetheless, such a criterion might not be true or suitable to be applied in every culture. An unqualified application of the I-E dimension which neglects the individual's cultural experiences, may bring harm to the client. It is essential to note that externality related to ascribing control to cultural forces, or to powerful others are different from that of ascribing control to chance and luck. For example, a study in Malaysia has shown that people with an external locus of control reported fewer depressive symptoms (Yeoh et al., 2017). In a collectivist culture which emphasizes interdependence among its members, expecting others to take responsibility for one's well being is deemed common. Also, there might be real socio-political challenges that make a minority client realistically think that there is a discrepancy between his/her ability and the achievement. Sue \& Sue (2016) suggested, only counsellors who know how to differentiate the meaning of external control dimension can benefit from the I-E continuum, as high externality can be attributed to (a) impersonal forces like luck, (b) cultural practices that are viewed as common and benevolent, and (c) real sociopolitical challenges, such as racism and discrimination.

The locus of responsibility, another key dimension in worldview, refers to the extent to which an individual or system bears responsibility or blame (Jones as cited in Derald Wing Sue \& Sue, 2016). An individual who holds an internal locus of responsibility (IR) (a) emphasizes the understanding of an individual's motives, values, feelings and objectives, (b) attributes their success or failure to his/her skills or personal shortcomings, and (c) views success as an outcome related to one ability and effort. Meanwhile, individuals with situation-centered orientation (ER) believe that sociocultural and sociopolitical environments are much more powerful than individuals. The socioeconomic system, not necessarily based on personal attributes, determines success or failure (Sue, 1978). In essence, the former blames the individual, whereas the latter places more emphasis on the system itself. Knowing the locus of responsibility enables counsellors to understand clients' perceptions and behaviors. External locus of responsibility among minorities seems to link with collective social action, civil rights activities, racial-ethnic identity, and better psychological health (Sue, 1978). In other words, minorities with situation-centered orientation are generally much more likely to join collective action, and have a more positive attitude towards their own culture or history. While placing emphasis on the person has its own benefits, defining the problem solely as a personal issue will risk the society overlooking the influence of external factors, and to preserve the social structures which might be unhealthy. Therefore, a counsellor may need to view the locus of responsibility for minorities, or socially devalued groups in a different lens. Placing the blame for one's failure on internal factors might be too harsh, or intropunitive for minorities.

Both the locus of control and locus of responsibility are psychological orientations which are independent of one another. Both can be positioned on the continuum in such a way that they intersect, hereby generating four quadrants: (I) internal locus of control - internal locus of responsibility (IC-IR); (II) external locus of control internal locus of responsibility (EC-IR); (III) external locus of control - external locus of responsibility (EC-ER), and (IV) internal locus of control - external locus of responsibility (IC-ER). Each quadrant represents a distinct way of looking at life, i.e., different worldviews.

\subsection{Internal Locus of Control (IC)-Internal Locus of Responsibility (IR)}

$\mathrm{Ng}$ (2007) stated that Malaysians are generally diverse based on their mental health views and help-seeking alternatives. Most of the psychiatric patients in Malaysia first sought magico-religious treatment, before seeking 
professional care $(\mathrm{Ng}, 2007)$. Hence, although multicultural counseling is based on the universal principles of counseling psychology, it is very difficult for many counselors to practice without any recourse toward religion (Siti Aishah \& Peh Kai, 2014). As previously stated, people with a high level of internal personal control (IC) feel that they have the power over their destiny, and that their actions have an impact on the consequences. Similarly, people with a high internal locus of responsibility (IR) relate their status and life circumstances to their personal attributes; i.e., success is credited to one's own efforts, while failure is assigned to one's flaws or deficiencies. The American society is perhaps the best example of the IC-IR paradigm.

Since most of the counseling models are from the United States of America, most Western-trained counsellors believe that people are responsible for their own behaviors, and that they can improve their position in life through their own efforts. Consequently, clients are expected to take the burden for change. Nevertheless, such an approach might be inappropriate while working with clients from different cultures. For instance, in Asian countries like Japan, Malaysia and the Philippines, assertiveness (i.e., higher personal control) might be viewed as a source of friction, as more emphasis is placed on preserving harmony (Niikura, 2000). Therefore, an IC-IR counselor needs to refrain from jumping into conclusion and labelling the client's behavior as deviant or negative, when the client holds different locus of responsibility, because the individual/system blame continuum may have a differing meaning for different cultural groups.

\subsection{External Locus of Control (EC)-Internal Locus of Responsibility (IR)}

Individuals in this quadrant are described as marginal individuals. They are much more prone to accept the dominant culture's idea of self-responsibility, while having little practical control over how they are defined by others. They deny racism exists, believe that their own people's plight is due to laziness, stupidity, and keep clinging to outdated traditions. They also reject their own cultural heritage, exhibit racial self-hatred, accept White social, cultural, and institutional standards, perceive physical features of White men and women as attractive, and believe that their ethnicity is a handicap in Western society (Sue, 1978).

In working with EC-IR minority clients, equal and acceptance relationships between the counselor and client must be stressed. This is because white counselors might be viewed as more competent and preferred than counselors of the client's own race. If unaware of such dynamics, the counsellor might overlook the valuable resources that come with an EC orientation, or reinforce the client's self-hate unconsciously. The approach of focusing on emotion might not be comfortable for EC-IR minority clients because it can expose self-hatred and understanding that they cannot escape their racial and cultural heritage. A culturally sensitive counsellor must (a) assist the client in comprehending the specific dominant-subordinate political forces that have resulted in this dilemma, and (b) assist the client in distinguishing between positive attempts to acculturate, and negative rejection of one's own cultural values (Sue, 1978).

\subsection{External Locus of Control (EC)-External Locus of Responsibility (ER)}

In the face of oppression, a person with a high level of system-blame and external control might feel helpless and believe that there is little one can do to change the situation. There are two possibilities to why an individual holds an EC orientation: (a) they have given up; or (b) they are trying to placate those in power. Individuals in the former group internalize their powerlessness despite being aware of the external causes of their situation. When marginalized groups learn that their actions have little impact in the environment, they develop a sense of helplessness. As a result, many may simply give up in trying to reach their personal aspirations. On the other hand, the placater conforms due to the need of survival in an oppressive environment. Because the social forces are seen as being too powerful to combat, many placaters choose to keep a low profile, and suffer the inequalities or unfair treatment in silence, yet they might not give up in their attempts to achieve personal goals yet. As direct displays of anger and resentment are risky, these groups of people might be much more inclined to express their feelings indirectly.

EC-ER clients, unlike EC-IR clients, are aware of the political forces which have oppressed them. They might display EC responses as mentioned, e.g., showing respectful or submissive behavior, and do not take the counselor's word that 'they are in control of their own destiny' seriously. Ineffective counsellors might not realize the basis of the client's behaviors, and perceive that the client is passive and lacks motivation. Conversely, a culturally effective counselor would (a) teach the clients new coping techniques; (b) empower them to experience success; and (c) acknowledge their personal and cultural identity (Sue, 1978).

\subsection{Internal Locus of Control (IC)-External Locus of Responsibility (ER)}

Individuals with a high internal control and system-focus feel that, given the opportunity, they can alter events in their own lives. They refuse to believe that their current situation is the result of a flaw in themselves. External 
barriers like discrimination, prejudice, and exploitation, on the other hand, are realistically perceived as impeding their ability to achieve their objectives (Sue, 1978). As described previously, IC orientation is linked with greater self-confidence/efficacy, higher aspirations, etc., and EC orientation is correlated to participation in social collective actions. Hence, this group of people normally feel pride in their racial and cultural identity, and they tend to challenge the unjust treatment / social forces.

In dealing with clients from this quadrant, counselors must be mentally prepared, in the sense that their credibility and trustworthiness might be challenged, especially if the counselors are members who come from cultural groups that enjoy privilege, e.g., higher SES, being White, etc. Besides, it is expected that clients might; (a) not easily disclose themselves; (b) play a more active role in the counseling process and (c) demand action from the counselor (Sue, 1978).

To summarize, the concept of worldview suggested by Derald Wing Sue (1978) offers a great insight into mental health practitioners for understanding themselves, their clients, and predicting the dynamics/possible biases during the session. The client's problem definitions and specific counselling skills are differentially associated with a particular worldview. The IC-ER counsellor may employ more action-oriented approaches, whereas the IC-IR counsellors may be non-directive in terms of their interaction with clients, as the control and responsibility for change lies with the clients. Research has revealed that the IC-ER Asian Americans see their counselors as being much more credible when employing a directive rather than non-directive approach (Atkinson et al., as cited in Derald Wing Sue, 1978). Therefore, counselors who have greater knowledge of their own and their client's worldviews will be able to better grasp a wide range of the client's experiences, challenges, aspirations, and ways of being during the counselling process. A culturally competent counsellor is one who can develop a broader range of responses which are consistent with the lifestyles and values of the culturally different clients. Also, counselors must have a more balanced view of each quadrant of worldview, as each worldview has its positive aspects. For instance, the individual responsibility and achievement of orientation of a quadrant IC-IR, biculturalism, and cultural flexibility of the quadrant EC-IR, has the ability to compromise and adapt to life conditions of the quadrant EC-ER, and collection action and social concern of the quadrant IC-ER, which need not be mutually exclusive. Thus, a counselor plays an essential role in assisting clients to integrate components of each worldview to enhance their effectiveness and psychological wellbeing (Sue, 1978).

\section{Gender and Personality}

The term 'gender' has varied meanings in different cultures, and it evolves with time. The most common definition is the one stated by Goof, Gilbert and Scher (as cited in Cornish et al., 2010), which defines gender as "psychological, social, and cultural features and characteristics frequently associated with the biological categories of male and female" (p. 376). Most civilizations have traditionally been patriarchal, meaning that men have had a greater access to, and control over resources than women, resulting in a greater authority. The inequality of power between gender, although it is lower today, still exists in today's world. To illustrate, women are still paid less for equal jobs, and women are still expected to be responsible for the house chores and child-care, even when both partners are working.

In Malaysian context, men are supposed to be more involved in traditionally masculine household activities (i.e., home repairs and family administration) and women are expected to be more involved in traditionally female household chores, according to traditional gender norms (i.e., childcare or shopping). As a result, these findings confirm that as men's feeling of masculinity declines, they are more likely to participate in domestic duties and contribute more to housework (Endut et al., 2020)

From a patriarchal viewpoint, the idea that men and women are diametrically opposed has been reinforced. For instance, females have always been linked with the body (e.g., sexuality, childbirth, emotionality), whereas males have always been associated with the mind (e.g., intellect and rationality) (as cited in Cornish et al., 2010). Girls are expected to be obedient, excellent moms, selfless, reliant, and trustworthy. On the contrary, pressure is placed on boys to be outgoing, independent, and assertive. Despite a substantial amount of evidence indicating that the differences in men's and women's traits and aptitudes are minor, and that similarities are more common, many still obsess with the differences. Books such as 'Men Are from Mars, Women Are from Venus' have gained significant popularity. This kind of distorted perceptions and social expectations can ultimately harm both men and women, because not all men are powerful or competitive, and not all women are emotional or less competent. The inability to meet all the gender role demands have resulted in psychological distress, such as paranoia, depression, and psychoticism (Robinson-Wood, 2017).

To be competent with respect to therapeutic practice with people from different genders, it is recommended that mental health practitioners gain an awareness of the gender role socializations and stereotypes across cultures. 
Practitioners need to review their own values and attitudes towards different genders. Mental health professionals who are unaware of the significance of gender in their own lives or in society may accidentally support the status quo, alienate the client, or unduly perpetuate their sense of pathology (Good et al. as cited in Cornish et al., 2010), There are also possibilities where they unintentionally impose their own, unexamined gender expectations on their clients. Besides, they may fail to see how gender fits within a woman's multiple identities, and impose a one-size-fits-all image based on their own cultural values. Without the correct understanding of a client's context, mental health practitioners might misdiagnose and put the blame on clients over things that might be out of their control. Counselors must also recognize that there might be variability within each gender group. Hence it is crucial for counselors to learn and explore gender identity models. Some of the examples of gender-specific models are the Key model (Scott \& Robinson, 2001), Downing and Roush's (1985) feminist identity development model, and Hoffman's (2006) model of feminist identity (as cited in Hays \& Erford, 2017).

\section{Conclusion}

Culture evolves over time, so do the cultural identities and the efficacy of counseling to maintain relevance to the intended population, cultural norms must be considered. The formation of cultural identity is very complex, and involves many aspects, apart from the three dimensions that were discussed in this paper, i.e., religious beliefs, worldview, and gender. As a guideline, counselors should refer to the Tripartite Development of Personal Identity, to identify the characteristics that are entirely unique to an individual, for example, other traits that are common within the client's cultural group, and the universal characteristics that are common to everyone. Nevertheless, counselors should always remember that we are not able to give our clients things that we do not have. Therefore, counselors should always search within themselves, how culture shapes and influences their opinions, assumptions, and beliefs. Only then can counselors avoid harm to the client through countertransference, or value imposition, and be much more culturally competent.

\section{References}

Cashwell, C. S., \& Young, J. S. (2011). Integrating spirituality and religion into counseling: A guide to competent practice (2nd ed.). American Counseling Association.

Cornish, J. A. E., Schreier, B. A., Nadkarni, L. I., Metzger, L. H., \& Rodolfa, E. R. (Eds.). (2010). Handbook of multicultural counseling competencies (1st ed.). John Wiley \& Sons.

Department of Statistic Malaysia. (2011). 2010 Population and Housing Census of Malaysia. Retrieved from https://www.dosm.gov.my/v1/index.php?r=column/ctheme\&menu_id=L0pheU43NWJwRWVSZklWdzQ4 TlhUUT09\&bul_id=MDMxdHZjWTk1SjFzTzNkRXYzcVZjdz09

Department of Statistics Malaysia. (2021). Demographic Statistics First Quarter 2021, Malaysia. Retrieved from https://www.dosm.gov.my/v1/index.php?r=column/cthemeByCat\&cat=430\&bul_id=aVlJRDAvbjhWWEh Qa1YvSWhsSjF3QT09\&menu_id=L0pheU43NWJwRWVSZklWdzQ4TlhUUT09

Endut, N., Bagheri, R., Azman, A., Hashim, I. H., Selamat, N. H., \& Mohajer, L. (2020). The Effect of Gender Role on Attitudes Towards Inequitable Gender Norms Among Malaysian Men. Sexuality \& Culture, 24, 2113-2136.

Frazier, R. E., \& Hansen, N. D. (2009). Religious/spiritual psychotherapy behaviors: Do we do what we believe to be important? Professional Psychology: Research and Practice, 40(1), 81-87. American Psychological Association. https://doi.org/10.1037/a0011671

Hasan, S., Yong, C., Babar, M., Naing, C., Hameed, A., Baig, M., ... Kairuz, T. (2011). Understanding, Perceptions and Self-use of Complementary and Alternative Medicine (CAM) among Malaysian Pharmacy Students. BMC Complementary and Alternative Medicine, 11, 95. https://doi.org/10.1186/1472-6882-11-95

Hassan, S. A., \& Peh, K. S. (2014). An Islamic perspective on multicultural counselling: A Malaysian experience of Triad Training Model (TTM). Middle-East Journal of Scientific Research, 19, 54-60. Retrieved from http://psasir.upm.edu.my/id/eprint/36425/

Hays, D. G., \& Erford, B. T. (2017). Developing multicultural counseling competence (3rd ed.). Pearson.

Ibrahim, F. A., \& Heuer, J. R. (2013). Chapter 19 - The Assessment, Diagnosis, and Treatment of Mental Disorders among Muslims (F. A. Paniagua \& A.-M. B. T.-H. of M. M. H. (Second E. Yamada, Eds.; pp. 367-387). Academic Press. https://doi.org/https://doi.org/10.1016/B978-0-12-394420-7.00019-9

Ibrahim, F., \& Heuer, J. (2016). Worldview: Implications for Culturally Responsive and Ethical Practice (pp. 51-75). https://doi.org/10.1007/978-3-319-18057-1_3 
Keshavarz, S., \& Baharudin, R. (2013). Perceived parenting style of fathers and adolescents' locus of control in a collectivist culture of Malaysia: The moderating role of fathers' education. The Journal of genetic psychology, 174(3), 253-270.

Khoshbooii, R., Hassan, S. A., Deylami, N., Muhamad, R., Engku Kamarudin, E. M., \& Alareqe, N. A. (2021). Effects of Group and Individual Culturally Adapted Cognitive Behavioral Therapy on Depression and Sexual Satisfaction among Perimenopausal Women. International journal of environmental research and public health, 18(14), 7711.

Koltko-Rivera, M. E. (2004). The Psychology of Worldviews. Review of General Psychology, 8(1), 3-58. https://doi.org/10.1037/1089-2680.8.1.3

Lim, A., Hoek, H. W., Ghane, S., Deen, M., \& Blom, J. D. (2018). The Attribution of Mental Health Problems to Jinn: An Explorative Study in a Transcultural Psychiatric Outpatient Clinic. Frontiers in Psychiatry, 9, 89. https://doi.org/10.3389/fpsyt.2018.00089

Ng, W. S. (2007). Psychotherapy in Malaysia-an overview. Mental Health and Learning Disabilities Research and Practice, 4(2), 205-217.

Niikura, R. (2000). Assertiveness Among Japanese, Malaysian, Filipino, and U.S. White-Collar Workers. The Journal of Social Psychology, 139, 690-699. https://doi.org/10.1080/00224549909598249

Jaladin, R. A. M. (2013). Barriers and challenges in the practice of multicultural counselling in Malaysia: A qualitative interview study. Counselling Psychology Quarterly, 26. https://doi.org/10.1080/09515070.2013.793046

Jaladin, R. A. M., Simmonds, J. G., \& Joseph, C. (2020). Professional counsellors' perceptions and experiences of multicultural counseling in Malaysia: A qualitative study. Journal of Nusantara Studies (JONUS), 5(2), 261-281. https://doi.org/10.24200/jonus.vol5iss2pp261-281

Robinson-Wood, T. L. (2017). The convergence of race, ethnicity, and gender: Multiple identities in counseling. SAGE Publications. https://doi.org/10.4135/9781071800737

Rotter, J. B. (1966). Generalized expectancies for internal versus external control of reinforcement. Psychological Monographs: General and Applied, 80(1), 1-28. American Psychological Association. https://doi.org/10.1037/h0092976

Scott, D. A., \& Robinson, T. L. (2001). White male identity development: The key model. Journal of Counseling \& Development, 79(4), 415-421.

See, C. M., \& Ng, K.-M. (2010). Counseling in Malaysia: History, Current Status, and Future Trends. Journal of Counseling \& Development, 88(1), 18-22. https://doi.org/https://doi.org/10.1002/j.1556-6678.2010.tb00144

Sue, D. W. (1978). Eliminating cultural oppression in counseling: Toward a general theory. Journal of Counseling Psychology, 25(5), 419-428. https://doi.org/10.1037/0022-0167.25.5.419

Sue, D. W., \& Sue, D. (2016). Counseling the culturally diverse: Theory and practice (7th ed.). John Wiley \& Sons, Inc.

Tan, M. M., Su, T. T., Ting, R. S.-K., Allotey, P., \& Reidpath, D. (2020). Religion and mental health among older adults: Ethnic differences in Malaysia. Aging \& Mental Health, 1-8. https://doi.org/10.1080/13607863.2020.1799939

Voon, S. P., \& Jaladin, R. A. M. (2017). The relationship between Malaysian counselor's multicultural counseling competence and client satisfaction. Malaysia Online Journal of Psychology \& Counselling (MOJPC), 1(1). Retrieved from https://mojc.um.edu.my/article/view/5562

Yeoh, S. H., Tam, C. L., Wong, C. P., \& Bonn, G. (2017). Examining Depressive Symptoms and Their Predictors in Malaysia: Stress, Locus of Control, and Occupation. Frontiers in Psychology, 8, 1411. https://doi.org/10.3389/fpsyg.2017.01411

\section{Copyrights}

Copyright for this article is retained by the author(s), with first publication rights granted to the journal.

This is an open-access article distributed under the terms and conditions of the Creative Commons Attribution license (http://creativecommons.org/licenses/by/4.0/). 